\title{
Como consumidores de baixa renda estabelecem uma relação entre o autocontrole, a consciência de preço e o consumo sustentável?
}

\section{How do low income consumers perceive the relationship among self-control, price awareness and sustainable consumption?}

\author{
Helton Rafael Ferreira do Nascimento \\ Universidade Federal de Pernambuco - UFPE - Brasil \\ elton.chapions@gmail.com \\ ORCID: 0000-0002-9658-368X \\ Cristiane Salomé Ribeiro Costa \\ Universidade Federal de Pernambuco - UFPE - Brasil \\ cristiane.costa@ufpe.br \\ ORCID: 0000-0002-9327-9164 \\ Elielson Oliveira Damascena \\ Universidade Federal de Pernambuco - UFPE - Brasil \\ elielson.damascena@ufpe.br \\ ORCID: 0000-0002-6916-931X \\ Flávia Zimmerle da Nóbrega Costa \\ Universidade Federal de Pernambuco - UFPE - Brasil \\ flavia.zimmerle@ufpe.br \\ ORCID: 0000-0002-9210-7889
}

\author{
Recebido: 11 Junho 2021 \\ Revisado: 02 Agosto 2021 \\ Aceito: 17 Agosto 2021
}

\begin{abstract}
Resumo
Objetivo: Esse trabalho buscou compreender como os consumidores de baixa renda, em suas decisões de compra, relacionam o autocontrole das despesas, a consciência de preço com o consumo sustentável. Metodologia: De natureza qualitativa e cunho interpretativista, essa pesquisa adotou a entrevista em profundidade como método de coleta; nosso corpus foi formado por 18 respondentes e utilizamos uma análise de discurso funcional. Resultados: nossos resultados apontaram a existência de três relações efetuadas pelos consumidores: eles entendem que contribuem com a sustentabilidade por gerar um menor descarte do lixo e provocar uma menor extração da matéria-prima e, ainda, ao fazê-lo, acreditam despertar o desejo de adoção de práticas ambientais. Contribuições: ao nos debruçarmos para uma perspectiva cotidiana de consumo construída a partir da visão do consumidor de baixa renda, contribuímos com o campo de estudos do consumo ao desvelar um comportamento de culturalmente singular; por sua vez, também desvelamos a contribuição de suas práticas para com os princípios da sustentabilidade, potencial que os estudos desse campo têm recorrentemente negligenciado
\end{abstract}

Palavras-chave: Autocontrole; consciência de preço; consumidor baixa renda; consumo sustentável.

\begin{abstract}
Goal: This work aimed to understand how down-market consumers relate their self-control spending and price awareness with sustainable consumption in their buying decision moments. Methodology: With a qualitative-interpretive nature research approach, this study adopted a deep interview as a technique of data collection, which corpus was composed by 18 respondents, and data analyzed by functional discourse method. Result: the research results pointed out that there are three relationship made up by consumers: they understand that there is a contribution for sustainability because they reduce the waste and the raw material extraction and, because of this, they believe they are awakening a desire to adopt positive environmental actions. Contributions: By leaning out on a perspective of daily consumption practices explained from down-market consumer point of view, we can contribute to consumption field of research uncovering a singular cultural behavior; we also contribute to the consumption field of research uncovering the down-markets consumer practices linked with sustainable principles, showing the potential of this target that has been recurrent neglected by sustainable consumption studies.
\end{abstract}


keywords: Financial self-control; price awareness; low-income consumer; sustainable consumption.

\section{Introdução}

Dentre os fatores levantados como potenciais causadores dos problemas ambientais apontados pelas discussões em torno da sustentabilidade, a pobreza se configura como um dos principais, devido à falta ou dificuldade de acesso das classes economicamente menos favorecidas a serviços essenciais como educação, energia, água, sistemas sanitários e coleta de lixo (Sachs, 2005; Beck \& Pereira, 2012; Hemais, Borelli, Casotti \& Dias, 2014). Apesar dessa menção, estudos acadêmicos ainda dão pouca atenção às questões relacionadas às pessoas de baixa renda nas investigações em torno da sustentabilidade (Sachs, 2005; Prahalad, 2006; Pacheco, 2019).

Conforme a questão econômica é vista como principal barreira para o consumo sustentável (Sachs, 2005; Hemais et al, 2014), Lodi e Hemais (2019) observam que consumidores de baixa renda não são vistos pelas empresas como público-alvo potencial para o consumo de produtos ambientalmente responsáveis, uma vez que esses produtos são em geral mais caros do que os tradicionais e sendo a renda um dos principais indicadores socioeconômicos limitantes do consumo desse grupo (Ghali-Zinoubiand \& Toukabri, 2019; Lodi \& Hemais, 2019).

Entretanto, fazer parte de classes sociais com renda mais altas não garante que comportamentos sustentáveis possam ocorrer (Al Mamun, Mohamad, Yaacob \& Mohíuddin, 2018). Pesquisas do campo do comportamento do consumidor, como as de Lim et al. (2013) e Nielsen e Hofmann (2021) apontam uma constante lacuna entre discurso e ação do consumo sustentável, avaliando que os indivíduos se dizem mais sustentáveis, mas não efetivam o consumo dessa forma. Um ponto em comum entre essas pesquisas é que grande parte dos entrevistados são de classe média e alta, o que leva ao entendimento de que os ganhos pessoais não devem ser considerados como indicadores fundamentais da relação positiva entre o consumo e prática responsável (Bacha, Strehlau \& Schaun, 2011; Duckworth \& Gross, 2014).

Autores como Zavestoski (2002) entendem que os fatores financeiros devem ser relacionados ao consumo sustentável, mas considerando o controle que estes exercem sobre as compras desnecessárias. Tendo por base um movimento voluntário de resistência ao consumo, esses autores apontam que indivíduos estão buscando comprar e descartar menos, motivados por questões econômicas, sociais e ambientais (Zavestoski, 2002; Kraemer, Silveria \& Rossi, 2012), controlando os seus gastos por meio do autocontrole financeiro e da consciência de preço (Duckworth \& Gross, 2014).

Dolan (2002) e Prahalad (2006) entendem que os consumidores de baixa renda apresentam uma maior consciência de preço e autocontrole porque evitam gastar dinheiro com o que não consideram importante para a sua subsistência. Devido a limitação de recursos financeiros e da dificuldade de acesso ao crédito, as pessoas de baixa renda tendem a tomar decisões mais respaldadas com base no valor de uso dos produtos que irão consumir, com decisões fundamentadas a partir do preço do produto (Milyavskaya, Inzlicht, Hope \& Koestner 2015; Lodi \& Hemais, 2019). Adicionalmente, consumidores de baixa renda muitas vezes usam a criatividade em reaproveitar aquilo que foi produzido em suas práticas cotidianas para beneficiar a si e a outros consumidores, evitando a compra de novos produtos (Bacha, Strehlau \& Schaun, 2011).

Contudo, apesar do reconhecimento de que o consumo sustentável acontece através de uma ação consciente tomada a partir do entendimento dos impactos gerados por determinada prática (Lima, Costa \& Felix, 2019; Phipps et al., 2013), deve-se considerar que os indivíduos de baixa renda, geralmente, apresentam uma alfabetização insuficiente para compreender a importância do autocontrole das despesas e da consciência de preço para a sustentabilidade e que, muitas vezes, o fazem sem compreender, de fato, os benefícios sociais, econômicos e ambientais inerentes ao processo (Shingler, 2009). Ainda, seguindo Peattie e Collins (2009), quando se fala em sustentabilidade, de modo geral, a compreensão do conceito pelas pessoas é limitada, pois é imediatamente vinculada apenas às questões relativas ao aspecto ambiental.

Neste âmbito, considerando que o Brasil é um país emergente onde a população é predominante de baixa renda - definida pelo Instituto Brasileiro de Geografia e Estatística (IBGE, 2018) como pessoas com renda mensal individual de até metade de um salário mínimo ou que ganham até 3 salários mínimos de renda familiar mensal - torna-se importante entender como acontece o comportamento sustentável a partir de classes sociais menos investigadas na literatura, focando não no tipo de produto sustentável que o consumidor de baixa renda pode comprar, mas, o seu contrário, o não consumo, ou compra de forma otimizada, e como esse indivíduo entende esse comportamento com relação a sustentabilidade (Duckworth \& Gross 2014; Aguiar, Farias, Gomes, \& Santos, 2015; Lodi \& Hemais, 2019). Diante do exposto, esta pesquisa objetiva investigar o entendimento dos indivíduos de baixa renda em torno da relação que estabelecem entre: o autocontrole das despesas, a consciência de preço e o consumo sustentável, a partir das suas práticas cotidianas. 
Embora existam estudos que já estabeleçam a relação entre os construtos aqui apresentados, como o de Costa, Silva e Campos (2020), que avaliaram percepção de preços e o autocontrole de despesas no âmbito do consumo de compra coletiva, esse estudo inova ao trazer em conjunto esses construtos em uma mesma investigação para avaliar a relação destes com o consumo sustentável, o que ainda não havia sido apresentado na literatura do comportamento do consumidor. Além disso, grande parte das investigações em torno da temática da sustentabilidade, como as de Antonetti e Maklan (2014), Ghali-Zinoubiand e Toukabri, (2019), Lima, Costa e Félix (2019) e Costa et al. (2021), e, estão centradas em identificar intenções comportamentais dos consumidores, o que na maioria das vezes não conseguem explicar a lacuna entre o discurso e a prática no consumo sustentável.

Partimos do princípio que as práticas de consumo dessa classe econômica se estabelecem, principalmente, a partir da coexistência de duas racionalidades: uma de ordem material, referente à escassez de recursos, e outra de ordem simbólica, ancorada nas dimensões relacionais (Chauvel \& Mattos, 2008) que, sendo de ordem cultural, contribuem para formação dos hábitos de compra (Silva \& Neto, 2018); ao mesmo tempo, indicam a complexidade em que estão envoltas (Gerhard, Sousa, Souza \& Peñaloza, 2016), e a insuficiência de se entender sua relação com a sustentabilidade apenas a partir de critérios sócio demográficos (Damázio, Coutinho \& Shigaki, 2020). Neste cerne, este estudo busca apresentar a relação entre percepção de preço e autocontrole com comportamento sustentável dentro de uma perspectiva cotidiana e construída a partir da visão do consumidor, de forma que possa contribuir para o entendimento do comportamento de consumo na sua realidade. Adicionalmente, esse estudo também visa contribuir com o campo do consumo e da sustentabilidade ao focar no público alvo de baixa renda que, a despeito do seu potencial em contribuir com os princípios da sustentabilidade (Prahalad, 2005; Hemais et al, 2014), vem sendo negligenciado nos trabalhos sobre o tema (Lodi \& Hemais, 2019).

\section{Fundamentação Teórica}

De modo a embasar as análises e discussões do estudo, neste tópico serão apresentados os fundamentos teóricos acerca do comportamento sustentável de consumo, do autocontrole do consumidor e da consciência de preço.

\subsection{0 comportamento sustentável de consumo}

Consumo sustentável existe quando os consumidores consideram o impacto de seu consumo na sociedade, no meio ambiente e na economia e usam recursos levando em consideração as gerações futuras e o bem-estar da sociedade atual (Phipps et al., 2013; Policarpo \& Aguiar, 2020). Estudos do marketing, como os de Peattie e Collins (2009), Antonetti e Maklan (2014) e Lima, Costa e Felix (2019) têm se voltado para analisar o comportamento sustentável dos consumidores com objetivo de identificar os fatores que podem levar os indivíduos a mudança de comportamento.

Neste cerne, predominam três modos de investigação: a) o consumo sustentável ambiental, que busca avaliar questões relacionadas à preservação do meio ambiente no comportamento de consumo; b) o consumo sustentável social, com a conscientização das pessoas sobre os impactos de suas ações na sociedade, e; c) o consumo sustentável econômico, aquele que evita desperdícios, conservando ou transformando a utilização de bens e que ajuda o social (Sachs, 2005; Prahalad, 2006; Hemais et al., 2014; Costa et al., 2021).

Sobre a questão econômica em específico, que se alinha ao objetivo deste estudo, consumidores que pautam o seu consumo em evitar o desperdício, transformando bens e consumindo de forma equilibrada com o seu orçamento, estão ao mesmo tempo protegendo o meio ambiente pela não compra em excesso e o não aumento do lixo na natureza, comprando apenas o que necessita, numa perspectiva de consumo utilitário e funcional (Anderson \& Markides, 2007; Bacha, Strehlau \& Schaun, 2011; Kraemer, Silveria \& Rossi, 2012).

Nesse contexto, a partir dos estudos de Hemais et al (2014), pode ser entendido que, geralmente, os consumidores em suas ações de redução de gastos podem ser: (i) proativos, que têm consciência do uso dos recursos e planejam mais os gastos; (ii) reativos, conforme suas limitações econômicas, têm uma maior consciência de preço e autocontrole das suas despesas e buscam agir de modo responsável no consumo e no reuso de produtos, e; (iii) preventivos, que evitam desperdícios e dão preferência a produtos com maior qualidade e durabilidade.

As explicações sobre os motivos que levam os indivíduos a desenvolverem um desses três tipos de comportamento percorrem diferentes abordagens (Dolan, 2002; Romani, Grappi, \& Bagozzi, 2013), e a renda é uma delas. Para Aguiar et al. (2015) a renda deve ser considerado como um fator motivador porque leva o indivíduo a agir intuitivamente por meio da suscetibilidade do autocontrole dos gastos ou pela consciência de preço. A prática de consumo sustentável tem sido apontada como mais latente nos indivíduos de baixa renda localizados nos países menos desenvolvidos dos continentes da África e 
América do Sul (Romani, Grappi, \& Bagozzi, 2013), embora tais pessoas possam apresentar menos predisposição na intenção de compra de produtos sustentáveis em virtude do preço mais alto de venda (Sachs, 2005; Prahalad, 2006). Desse modo, é a sua necessidade de autocontrole das despesas que as leva para a compra do que é necessário e, é a sua consciência de preço, que as leva a praticar a economia dos gastos (Lodi \& Hemais, 2019). Nesses casos, entende-se neste estudo que se configura, mesmo que de forma involuntária, as ações de em prol da sustentabilidade (Duckworth \& Gross, 2014; Baskentli, Sen, Du \& Bhattacharya, 2019).

\subsection{0 autocontrole do consumidor}

0 autocontrole do consumidor tem um foco autorregulatório (Vohs \& Baumeister, 2004), que faz parte da autodisciplina e planejamento acerca de como agir e pensar sobre a administração de seus comportamentos (Lens, Simons, \& Dewitte, 2001; Costa, Silva \& Campos, 2020). 0 autocontrole ganhou maior vigor a partir de estudos acadêmicos que mostraram a importância da conscientização no comportamento de consumo devido a dois fatores: a discrepância nos preços de alguns produtos e a compra compulsiva (O’Donoghue \& Rabin, 2001; Al Mamun et al., 2018).

De modo geral, o autocontrole é uma priorização de motivos que, geralmente, ocorre pela capacidade do indivíduo em identificar seus objetivos e, a partir daí, regular o seu comportamento (Inzlicht, Werner, Briskin \& Roberts, 2021). Isso acontece quando os consumidores identificam um conflito mediante uma decisão próxima, proveniente de razões abstratas, tais como as relativas à saúde, à sustentabilidade financeira ou à regulação emocional (Milyavskaya et al., 2015); ou ainda, quando os mesmos tendem a regular a sua atenção mediante a conscientização, a motivação e/ou ao comportamento diante do controle de seus impulsos, assim passando a refletir acerca das consequências de determinadas práticas (Dolan, 2002).

Locke e Lathan (2002), por exemplo, apontam que os indivíduos com maior autocontrole superam mais seus impulsos e conseguem juntar mais dinheiro ao longo da vida; para os autores, essa questão pode explicar melhor o comportamento dos indivíduos em relação à sua situação financeira do que a falta de educação nessa área. A educação financeira pode ser conquistada, diferente do autocontrole que não pode ser aprendido (Gathergood, 2012). Figueira e Pereira (2014) entendem que autocontrole representa a possibilidade de o consumidor evitar uma compra por impulso, evitando contribuir com o seu endividamento.

Desse modo, o autocontrole está diretamente vinculado à autodisciplina econômica, pois, para poderem manter suas despesas controladas, os indivíduos agem pautados nessa racionalidade. Tendo por base certa ação reflexiva presente em uma prática de consumo, o autocontrole pode ser considerado um importante fator de influência sobre o consumo sustentável. Os consumidores com autocontrole nas suas despesas apresentam comportamento condizente com a prática sustentável, tendo em vista que o limite de gastos, compra reduzida e/ou reaproveitamento, são práticas que impactam na sustentabilidade, mesmo que geralmente os indivíduos não se deem conta disso (Shingler, 2009; Milyavskaya et al., 2015).

Porém, a maioria dos estudos que investigam a sustentabilidade (Bacha, Strehlau \& Schaun, 2011; Baskentli et al., 2019), consideram as dimensões socioeconômicas e ambientais tendo por intuito minimizar o uso de recursos e materiais não renováveis, ou seja, priorizando focar no processo de compra de produtos que tenham sido produzidos de forma sócio ambientalmente responsáveis. Podemos entender que essa perspectiva continua favorecendo o consumo, pois apenas migra o foco do indivíduo sobre o que deve comprar. Contudo, considerar o autocontrole financeiro como uma perspectiva de redução de consumo, principalmente derivado de classes com rendas mais baixas, pode levar a entender esse perfil de indivíduo pautado no não-consumo que, consequentemente, produz menos desperdício e evita a compra por impulso; essas são ações podem ser entendidas como relacionadas ao comportamento sustentável do consumo (Zavestoski, 2002; Nielsen \& Hofmann, 2021).

Afinal, comportamentos que possuem como fundamento a disponibilidade financeira, tendem a diferir categoricamente daqueles que não possuem, pertencendo, assim, a tipos distintos de modos de consumir, que precisam de uma melhor investigação.

\subsection{Consciência de preço}

De acordo com Gao, Zhang e Mittal (2017) e Milan, Toni, Lima, \& Eberle (2017), a consciência de preço dos consumidores é representada por aqueles indivíduos que apresentam sensibilidade ao preço, ou seja, que costumam analisar se de fato os preços são justos com o que os produtos estão propondo em eficiência e qualidade, e se o produto ou serviço vai trazer algum bem-estar para si ou para o meio. Esses consumidores, geralmente, são menos consumistas, pois tendem a não realizar compras por impulso. 
A consciência de preços dos consumidores se reflete nos seguintes hábitos: discernimento dos preços unitários dos produtos, comparação de preço antes da realização das compras, consciência em torno dos danos ecológicos que o consumo exagerado pode trazer, observação da rotulagem daquilo que estão comprando e entendimento das compensações financeiras e ambientais do consumo racional (Yang, 2019). Indivíduos com consciência de preço apresentam uma maior sensatez acerca do custo-benefício daquilo que vão consumir, bem como a qualidade dos produtos ou serviços que irão usufruir (Costa, Silva \& Campos, 2020).

Consumidores conscientes com relação ao preço tem uma preocupação maior quanto a poupança de recursos financeiros, consideram as experiências de compras anteriores e tendem a reinvestir o valor unitário do "que foi poupado" em seu orçamento semanal (Tamer, 2011; Lim, 2017). Estes, estão dispostos a gastar parte do tempo em se engajar a procurar por produtos com o custo menor (cerca de $40 \%$ a 50\%) fazendo suas escolhas com base nos preços que influenciam suas expectativas e, comumente usam as promoções para simplificar mentalmente a consciência de preço, sendo esses os fatores que fortemente influenciam seu comportamento de avaliação dos produtos (Gan, Pujawan \& Suparno, 2015; Lodi \& Hemais, 2019).

É importante destacar que a consciência e a sensibilidade ao preço são fatores que compõem abordagens diferentes para avaliar a influência do preço nas decisões de compra dos consumidores, apesar de uma levar a outra (Aguiar et al., 2015). De acordo com Mortimer e Weeks (2019) e Shin e Ji (2021), a consciência de preço se refere ao conhecimento obtido pelo consumidor sobre o preço de determinados produtos, geralmente baseado em informações, em pesquisas e na comparação efetuada entre produtos similares de uma mesma categoria, o que permite o indivíduo avaliar os benefícios ofertados. Já a sensibilidade ao preço estaria relacionada à reação do consumidor quanto às alterações, aproximadamente, no preço de produtos (Binkley \& Bejnarowicz, 2003). Nesse sentido, a sensibilidade ao preço é entendida como uma consequência da consciência de preço de um produto, o que faz com que um indivíduo seja menos ou mais vulnerável a tais alterações.

Em geral, estudos sobre a influência de preço nas abordagens da sustentabilidade focam em avaliar a sensibilidade ao preço dos indivíduos na intenção de compra de produtos sustentáveis, especialmente porque produtos nesta categoria possuem preços mais altos do que os oferecidos sem esse benefício; assim, em relação do meio ambiente, a sensibilidade ao preço é priorizada em detrimento da consciência de preço dos consumidores sobre produtos (Al Mamun et al., 2018).

\section{Procedimentos Metodológicos}

Nosso estudo é de natureza qualitativa e insere-se no paradigma interpretativista (Denzin \& Lincoln, 1994; Creswell, 2007; Gil, 2008). A entrevista individual em profundidade foi escolhida como técnica de coleta, sendo feita de forma presencial. A mesma foi constituída por 13 perguntas abertas (Vide Quadro 1), organizadas visando acessar o entendimento dos sujeitos acerca de suas ações de autocontrole e consciência de preço, bem como, entender de que modo eles as relacionam com o consumo ambiental sustentável. Buscamos segmentar as questões da pesquisa de acordo com os construtos amplamente trabalhados nos estudos do comportamento do consumidor, e assim distribuímos: quatro questões se voltaram para entender as ações de autocontrole, quatro para a compreensão da consciência do preço e cinco para entender como esses consumidores percebem suas ações em relação ao consumo sustentável.

As perguntas foram inspiradas no que discutem os estudos aqui consultados. Assim, em relação às ações de autocontrole, nossas questões se pautaram na ideia central de que essa prática do consumidor se dá a partir de certa reflexão sobre o processo de consumo e a consequente priorização dos motivos de escolha; e, como essa é dada vinculada à disciplina econômica, termina por diminuir a compra por impulso (Lens, Simons, \& Dewitte, 2001; Dolan, 2002; Locke \& Lathan, 2002; Zavestoski, 2002; Figueira \& Pereira, 2014; Vosgerau, Scopelliti \& Huh, 2020; Nielsen \& Hofmann, 2021). Em relação às questões de consciência de preço, nos embasamos no entendimento de que essa depende fundamentalmente da conquista da clareza pelo consumidor em relação ao custo-benefício dos produtos que adquire, o que certamente os desperta para fazer pesquisas de preço e aproveitar as promoções (Gan, Pujawan \& Suparno, 2015; Lodi \& Hemais, 2019; Yang, 2019; Costa, Silva \& Campos, 2020). Por fim, as cinco últimas questões buscam entender a percepção do consumidor em relação ao consumo sustentável e como ele as relaciona com as questões acima tratadas; A ideia central na qual nos pautamos foi a de que a condição de renda e a intuição seriam fatores-chaves para uma prática sustentável, o que faz essa ocorrer voluntária ou involuntariamente (Sachs, 2005; Prahalad, 2006; Romani, Grappi, \& Bagozzi, 2013; Duckworth \& Gross, 2014; Aguiar et al. 2015; Baskentli et al., 2019; Lodi \& Hemais, 2019); assim priorizamos questionar se eles entendiam o que era a sustentabilidade e de que modo vinculavam suas formas de consumir com a questão. 


\section{Quadro 1: Roteiro da entrevista}

\begin{tabular}{|c|c|c|}
\hline \multirow{4}{*}{$\begin{array}{c}\text { Ações de } \\
\text { autocontrole }\end{array}$} & 1 & Você desenvolve alguma ação para controlar as suas despesas? \\
\hline & 2 & Você possui algum planejamento do seu dinheiro? \\
\hline & 3 & Você se considera uma pessoa disciplinada com seu dinheiro? \\
\hline & 4 & $\begin{array}{l}\text { Você tem controle do seu dinheiro? } 0 \text { que te leva a ter esse controle (caso tenha)? } 0 \\
\text { que faz com que você não tem controle (caso não tenha)? }\end{array}$ \\
\hline \multirow{4}{*}{$\begin{array}{l}\text { Ações de } \\
\text { consciência de } \\
\text { preço }\end{array}$} & 5 & O que você faz para poupar o seu dinheiro? \\
\hline & 6 & Você faz comparação de preço quando efetua suas compras? \\
\hline & 7 & Você tem consciência dos preços dos produtos quando desenvolve suas compras? \\
\hline & 8 & O que você faz com o dinheiro que sobra depois que você faz suas compras? \\
\hline \multirow{5}{*}{$\begin{array}{l}\text { Percepção de } \\
\text { comportamento } \\
\text { sustentável de } \\
\text { consumo }\end{array}$} & 9 & Você sabe o que é sustentabilidade? \\
\hline & 10 & Você acredita praticar a sustentabilidade? \\
\hline & 11 & $\begin{array}{l}\text { Você julga que existe alguma relação entre controlar seu dinheiro e, de algum modo, } \\
\text { praticar a sustentabilidade ambiental? }\end{array}$ \\
\hline & 12 & $\begin{array}{l}\text { Você julga que existe alguma relação entre buscar informações de preço dos } \\
\text { produtos e, de algum modo, praticar a sustentabilidade ambiental? }\end{array}$ \\
\hline & 13 & $\begin{array}{l}\text { Você acredita que controlar suas despesas e pesquisar informações de preço de } \\
\text { produtos podem gerar um comportamento mais sustentável em relação ao meio } \\
\text { ambiente no consumidor? Se sim, de que modo isso pode vim a acontecer? }\end{array}$ \\
\hline
\end{tabular}

Fonte: elaborado pelos autores (2020)

A construção do corpus seguiu os princípios estabelecidos por Bauer e Aarts (2002), e buscou atender aos critérios de confiabilidade e validade dessa forma de pesquisa (Paiva, Leão \& Mello, 2011). Visando atender aos critérios de confiabilidade e validade, essa construção buscou maximizar a variedade de representações: a idade dos entrevistados variou entre 20 e 50 anos, o grupo foi formado por pessoas com profissões e estado civil diferentes, e ainda, pertencentes a núcleos familiares com e sem filhos, mas todos moradores do município de Garanhuns em Pernambuco (Vide Quadro 2). A maior parte dos entrevistados foi do sexo feminino. Quanto à faixa etária, nossa escolha vai ao encontro da observação de Duckworth e Gross (2014), de que o público nessa faixa apresenta maior autocontrole das despesas e consciência de preço. Quanto ao percentual predominantemente feminino, a escolha adequa-se à informação do IBGE (2019), de que no Brasil as mulheres são responsáveis pelo controle da situação financeira da família. Cabe destacar que no município onde foi realizada a pesquisa, o salário médio mensal é de 1.8 salários mínimos, com rendimentos mensais de até meio salário mínimo por pessoa, o que representa $43.8 \%$ da população nessas condições (IBGE, 2019).

Quadro 2 - Perfil demográfico dos entrevistados

\begin{tabular}{|c|c|c|c|c|}
\hline Entrevistados | Sexo & Profissão & Idade & Estado civil & $\begin{array}{c}\text { Quantidade de } \\
\text { filhos }\end{array}$ \\
\hline \multirow{5}{*}{ Feminino } & Estudante & 20 & Casada & 01 \\
\cline { 2 - 5 } & $\begin{array}{c}\text { Assistente } \\
\text { Administrativo }\end{array}$ & 21 & Solteira & - \\
\cline { 2 - 5 } & Servidora pública & 43 & Solteira & 02 \\
\cline { 2 - 5 } & Professora & 50 & Casada & - \\
\cline { 2 - 5 } & Recepcionista & 22 & Solteira & - \\
\cline { 2 - 5 } & Estudante & 24 & Solteira & 02 \\
\hline
\end{tabular}




\begin{tabular}{|c|c|c|c|c|}
\hline \multirow{5}{*}{} & Pedagoga & 43 & Casada & 02 \\
\cline { 2 - 5 } & Recepcionista & 39 & Divorciada & - \\
\cline { 2 - 5 } & Autônoma & 31 & Casada & 02 \\
\hline \multirow{5}{*}{ Masculino } & Aposentada & 47 & Casada & - \\
\hline & Professora & 24 & Solteira & - \\
\cline { 2 - 5 } & Auxiliar de almoxarifado & 21 & Solteiro & 04 \\
\cline { 2 - 5 } & Montador de móveis & 47 & Divorciado & 03 \\
\cline { 2 - 5 } & Músico e autônomo & 45 & Casado & - \\
\cline { 2 - 5 } & Estudante & 19 & Solteiro & 03 \\
\cline { 2 - 5 } & Servidor publico & 39 & Divorciado & 02 \\
\hline
\end{tabular}

Nosso corpus foi formado por 18 entrevistas presenciais, cujos relatos foram gravados. 0 tempo médio das entrevistas foi de 42 minutos, o que gerou 90 páginas de transcrição, ou seja, uma média de cinco páginas por entrevistado. Inicialmente contactamos alguns respondentes por aplicativo de mensagem. Cinco participantes demonstraram interesse em participar. 0 grupo indicou outros potenciais participantes, que também foram acessados via aplicativo de mensagens e todos receberam primeiramente a pergunta de triagem acerca do perfil financeiro em que se encaixavam. Para estabelecer esse perfil, seguimos por critério a definição do IBGE (2018), que define pessoas de baixa renda como aquelas com renda mensal individual de até meio salário mínimo ou que ganham até 3 salários mínimos de renda familiar mensal.

No total, 21 pessoas retornaram à solicitação de realização da entrevista. Destes, 3 não se enquadraram no perfil de renda estabelecido, por isso, não foram contatados posteriormente. Os 18 indivíduos foram entrevistados em suas residências, o que facilitou a observação in loco de práticas de consumo relatadas nas entrevistas. A mesma foi conduzida com os responsáveis pela administração dos gastos, fossem esses de ordem familiar ou individual. A coleta foi encerrada por saturação, seguindo a orientação de Creswell (2007), pois as respostas dos últimos participantes já não traziam informações adicionais acerca da relação aqui analisada. 0 processo de coleta durou 30 dias e ocorreu no mês de janeiro de 2020 .

A técnica de análise que utilizamos foi a de discurso funcional que, conforme descrita por Gill (2002), volta-se para compreensão da ação que os discursos possuem em seus contextos de fala. Seguindo essa autora os processos analíticos de organização dos dados e da construção interpretativa ocorreram inter-relacionados. Para a organização do processo analítico, adotamos as três macro etapas indicadas por Gil (2008): redução, exibição e conclusão/verificação. Na primeira fase fizemos o agrupamento e a simplificação dos dados por temas. Na segunda, organizamos os agrupamentos de modo a possibilitar a análise sistemática de suas semelhanças e diferenças, bem como de seu interrelacionamento; aqui buscamos demarcar as funções dos trechos de fala em cada agrupamento. Por fim, na terceira fase, procedemos à interpretação. Essa foi orientada pela triangulação dos dados efetuada entre os agrupamentos e as funções, que fez emergir a significação de regularidades do conjunto de dados (Gil, 2008).

\section{Análise e discussão dos resultados}

Optamos por apresentar incialmente a triangulação de dados pois, apesar dessa encontrar-se na terceira fase analítica, ela conduz o leitor a um entendimento geral sobre os resultados, uma vez que esse processo fez emergir a significação das regularidades. Essas ligações são apresentadas na Figura 1.

\section{Figura 1 - Triangulação dos dados}




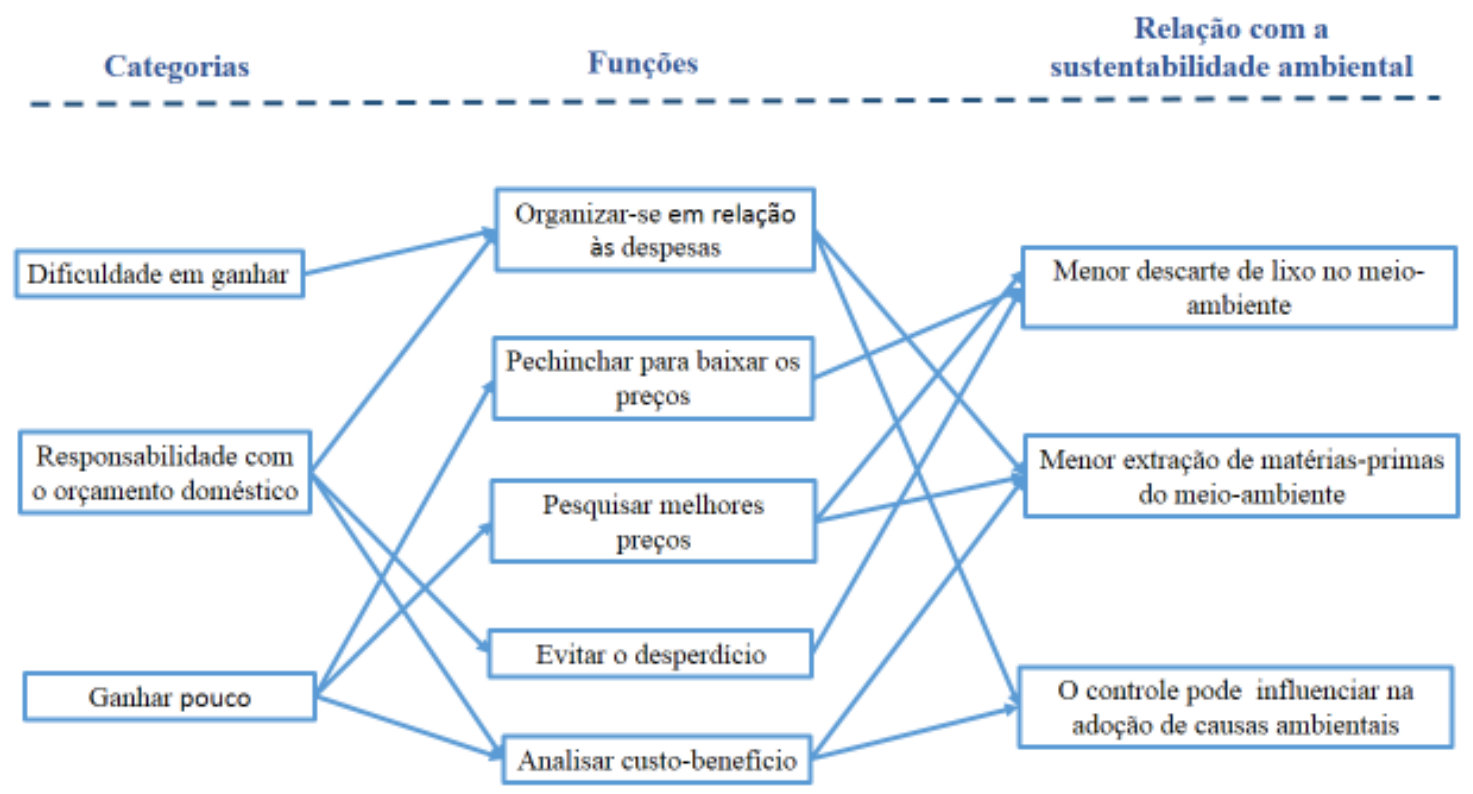

Fonte: elaborada pelos autores (2020)

Na primeira fase analítica, chegamos a três categorias, que se referem aos motivos do controle financeiro, apresentadas no Quadro 2. Embora tenham sido encontrados respondentes que não estabeleceram a relação entre a consciência de preço e o autocontrole com a preservação ambiental, encontramos três categorias que agrupam os sentidos encontrados nos dados.

\section{Quadro 2: Descrição das categorias}

\begin{tabular}{|l|l|}
\hline \multicolumn{1}{|c|}{ Categorias } & \multicolumn{1}{c|}{ Descrição } \\
\hline Dificuldade em ganhar & $\begin{array}{l}\text { Essa categoria engloba o reconhecimento da dificuldade para se ganhar dinheiro, } \\
\text { bem como dos esforços empreendidos para tanto. A codificação que originou essa } \\
\text { categoria envolve os sentidos: trabalhar muito para receber pouco e esforçar-se } \\
\text { para manter o trabalho. }\end{array}$ \\
\hline $\begin{array}{l}\text { Responsabilidade com } \\
\text { orçamento doméstico }\end{array}$ & $\begin{array}{l}\text { Trata-se da incumbência ou missão de manter o controle do orçamento familiar, } \\
\text { visando não deixar faltar as coisas mais essenciais. A categoria envolve a decisão } \\
\text { acerca do que e como comprar. A codificação dessa categoria foi feita a partir dos } \\
\text { sentidos: controlar orçamento, evitar desperdícios e planejar as compras }\end{array}$ \\
\hline Ganhar pouco & $\begin{array}{l}\text { Essa categoria envolve a compreensão de que a renda mensal é pequena e, por ser } \\
\text { quase insuficiente, demanda por ações acerca de definir o uso dos produtos } \\
\text { pensando na economia doméstica, tal como reaproveitamento de produtos dos } \\
\text { mais diferentes modos. A codificação dessa categoria conteve os seguintes } \\
\text { sentidos: priorizar compromissos, pesquisar e comparar preços, pechinchar, } \\
\text { reaproveitar e consumir menos }\end{array}$ \\
\hline
\end{tabular}

Fonte: elaborada pelos autores (2020)

Na segunda etapa analítica buscamos elucidar as funções (ação no contexto discursivo) ocupadas pelos discursos no interior de todas as categorias. Encontramos cinco funções apresentadas no quadro 3.

\section{Quadro 3: Funções e sua descrição}

\begin{tabular}{|l|l|}
\hline \multicolumn{1}{|c|}{ Funções } & \multicolumn{1}{c|}{ Descrição } \\
\hline $\begin{array}{l}\text { Organizar-se em relação } \\
\text { às despesas }\end{array}$ & $\begin{array}{l}\text { Essa função se constituiu das ações efetivadas para melhor distribuir a renda } \\
\text { mensal. Se refere aos modos de como isso acontece, incluindo: anotar os gastos ou } \\
\text { comprar no cartão, evitar as compras por impulso, tentar planejar as compras para o } \\
\text { período de promoções, ou tentar se prevenir guardando qualquer recurso que sobrar } \\
\text { no período. }\end{array}$ \\
\hline $\begin{array}{l}\text { Pechinchar para baixar o } \\
\text { preço }\end{array}$ & $\begin{array}{l}\text { A função trata da prática da negociação efetuada nas compras, na tentativa de fazer } \\
\text { render o orçamento perante as despesas. }\end{array}$ \\
\hline
\end{tabular}




\begin{tabular}{|l|l|}
\hline Pesquisar melhores preços & $\begin{array}{l}\text { Essa se mostrou uma função relevante em relação ao controle de despesas de } \\
\text { grande parte dos entrevistados, sendo amplamente citada. }\end{array}$ \\
\hline Evitar desperdícios & $\begin{array}{l}\text { A função se delineou tanto em relação a prática de comprar menos para sobrar } \\
\text { menos, quanto em relação às ações de reaproveitamento de sobras de alimentos e } \\
\text { de embalagens para outros fins, ao que se descreveu como "aprender a dar valor as } \\
\text { coisas". }\end{array}$ \\
\hline Analisar custo-benefício & $\begin{array}{l}\text { Essa função foi composta pela priorização de compras dos produtos de melhor } \\
\text { qualidade, pois sua durabilidade compensa seu preço mais elevado, evitando a } \\
\text { constante reposição. Também se referiu à prática de fazer as melhores escolhas no } \\
\text { ato de compra, priorizando embalagens e produtos recicláveis, que possam ser } \\
\text { vendidos ou doados para os catadores. }\end{array}$ \\
\hline
\end{tabular}

Fonte: elaborada pelos autores (2020)

De forma geral, os dados nos revelaram que poucos entrevistados conseguem poupar uma pequena quantia de seus ganhos, mas indicam que, quase sempre, surgem imprevistos e é necessário gastar o que se estava guardando. Estes, reiteram possuir consciência dos preços no ato das compras ao mesmo tempo em que comentam que nem sempre fazem comparação de preços. Apesar de grande parte dos respondentes afirmarem que não desenvolvem ações de autocontrole das despesas, visto que comprometem quase todo o salário em suas compras, desde o questionamento inicial direcionador da entrevista acerca do planejamento de suas despesas, as respostas já nos apontaram para as três categorias que constituíram a organização do nosso corpus de pesquisa: a dificuldade em ganhar, a responsabilidade com o orçamento doméstico e o fato de ganhar pouco. As três categorias refletem a preocupação genuína com o controle orçamentário.

A relação estabelecida na triangulação entre as categorias e as funções nos revelaram a existência de três ligações entre a consciência de preço, o autocontrole do consumidor com a sustentabilidade ambiental. Contudo, entendemos que, a maioria dos entrevistados nunca havia pensado sobre isso, ou seja, nosso questionamento despertou neles a consciência da existência dessa relação. A resposta do entrevistado 19 acerca de como estabelece a relação entre buscar informações de preço dos produtos e, de algum modo, praticar a sustentabilidade ambiental, exemplifica o caso:

\section{\#R19-257 - Não havia pensado sobre isso.}

No que diz respeito à sustentabilidade, a maioria dos entrevistados afirma ter conhecimento do que se trata, mas têm dúvidas na hora de externalizar isso. Assim, em conformidade com o que antecipou Shingler (2009), mesmo adotando aqui um recorte de entendimento mais corriqueiro, a sustentabilidade ambiental (Pettie \& Collins, 2009), os entrevistados demonstraram certo grau de desconhecimento acerca do que é o conceito. Por conseguinte, isso é estendido também para o que são suas práticas em favor dessa causa. Ao contrário do que comentou Al Mamun et al. (2018), essa ausência de práticas dos consumidores de baixa renda pode estar mais atrelada a falta de informação sobre sustentabilidade do que da ausência de recurso financeiro. Os trechos de fala abaixo ilustram esse [des]entendimento:

\#R9-136 - Eu pensava que sustentabilidade era eu me auto sustentar, conseguir me sustentar com os meus gastos. Mas eu vi que não, que não era bem assim.

\#R17-225 - Na verdade, eu sei o que é, mas não sei explicar. Por isso, eu não sei se eu pratico.

A partir desse ponto, seguiremos apresentando a análise das três relações com a sustentabilidade efetuadas pelos consumidores por linha de significados: partindo das categorias e passando pelas funções, mostramos como chegamos à relação. Cada linha segue ilustrada por recortes de fala, elucidando seus sentidos.

\subsection{Dificuldade em ganhar}

A dificuldade em ganhar emergiu vinculada à função organizar-se em relação às despesas, e levou ao entendimento de que a preservação se faz pela menor extração de matérias-primas do meioambiente. As colocações do entrevistado 12 elucidam a questão. Ele afirma planejar seus gastos, mas 
não se entende tendo um controle de seu dinheiro, pois costuma "descobrir um santo para cobrir outro". Por isso, sempre compara preços e busca poupar no que pode, ou seja, tenta controlar seus gastos, o que, de acordo com Mortimer e Weeks (2019) e Costa et al. (2020), reforçam o papel da consciência de preço do consumidor sobre o que se pretende adquirir, baseado em informações, pesquisas e na comparação efetuada entre produtos similares de uma mesma categoria:

\#R12-177 - A dificuldade para ganhar o dinheiro me leva a ter o controle

A relação que faz de suas práticas com a sustentabilidade ambiental reforça o pensamento de que a renda baixa não significa uma não contribuição para preservação do meio ambiente e, também pela tentativa de manter uma economia financeira, a durabilidade do produto se torna um ponto relevante para sua aquisição de modo a não gerar um maior consumo de recursos naturais (Kraemer, Silveria, Rossi, 2012; Lima, Costa \& Felix, 2019):

\#R12-183 - Isso é importante, quanto mais você consumir um produto que exige mais da natureza, maior será o dano, pois vai faltar recursos, vai chegar um ponto que vai sucumbir. E acho importante essa consciência, como a resposta que eu dei, eu prefiro compra um produto de melhor qualidade que dure mais do que um produto mais barato que, em compensação, terei um gasto maior com reparos. Isso pode impactar de modo positivo.

\subsection{Responsabilidade com o orçamento doméstico}

A responsabilidade com o orçamento doméstico surgiu vinculada à função evitar o desperdício. A respondente de número sete, por exemplo, afirma controlar seu orçamento, pois assume algumas obrigações perante a família. Contudo, seu dinheiro, por ser pouco, precisa ser controlado para "manter os compromissos em dia", evitando a compra desnecessária. Nesse sentido, quando questionada se pratica a sustentabilidade, ela responde:

\#R7-104 - Sim. 0 mínimo de descarte de insumos no meio ambiente, volta pra mim como benefícios.

Sua resposta indica que ela relacionou que sua compra controlada, portanto em volume menor, gera benefícios para ela e, em consequência, também gera um menor descarte, o que é também benéfico para o meio ambiente. Aqui se apresenta outra forma de se entender a prática de sustentabilidade, sendo voltada para um menor rejeite de elementos no ambiente a partir do melhor uso do que se consome; e este melhor uso derivado da tentativa de manter uma compra racional e utilitária (Dolan, 2002; Figueira \& Pereira, 2014; Vosgerau, Scopelliti \& Huh, 2020).

Ainda, responsabilidade com o orçamento doméstico vincularam-se às funções: organizar-se em relação às despesas e a analisar custo-benefício, levando o respondente a entender que o controle pode influenciar na adoção de causas ambientais. As colocações do respondente 16 nos ajudam a entender essa relação. Diante do encargo de bem distribuir o orçamento da casa, o entrevistado se considera razoavelmente disciplinado com seus gastos, busca manter o controle de suas despesas e avalia como extrema importância considerar o preço dos produtos em relação à sua durabilidade. Quando questionado se entendia que essa atitude poderia gerar um comportamento mais sustentável e como isso podia vir a acontecer, ele responde:

\#R16-243 - Sim acredito, organização e conhecimento são primordiais para se manter o orçamento mais equilibrado, dessa maneira [...] se pode conquistar novos admiradores dispostos a abraçar causas defendidas.

Apesar de podermos interpretar a adoção das causas ambientais como não sendo o motivo principal da ação retratada na fala, há esse benefício percebido pelo respondente a partir do planejamento e controle dos seus recursos financeiros, o que, seguindo as avaliações de Zavestoski (2002), podemos relacionar a um tipo de comportamento involuntário.

\subsection{Ganhar pouco}

A categoria ganhar pouco teve por função: analisar custo-benefício e, relacionando essas práticas com uma menor extração de matérias-primas do meio-ambiente. Os exemplos abaixo elucidam a ligação. 0 respondente nove afirma que não tem muito controle sobre seu orçamento e 
quase nada sobra ao fim do mês. Contudo, analisa que quando conhece o produto ele sabe quanto ele custa e o quanto ele dura e, por isso, faz comparação de preços e prioriza a qualidade do que está comprando. Percebe-se que a consciência na relação preço-qualidade do produto, a partir do discernimento do preço unitário do produto, se apresenta como parte do processo de tomada de decisão, que conduz o respondente a um autocontrole dos seus gastos (Aguiar et al., 2015; Yang, 2019; Nielsen \& Hofmann, 2021).

\#R9-131 - [...] quando eu conheço o produto e sei que ele está no preço elevando, eu não o compro. Eu prefiro comprar um produto bom que eu conheço pelo preço elevado, do que um ruim que está no preço baixo. Então, eu faço uma comparação sim de preço.

Quando o perguntamos se o fato de controlar suas despesas e pesquisar informações de preço de produtos podem gerar um comportamento mais sustentável em relação ao meio ambiente, ele afirma:

\#R9-137 - Se evitarmos gastos desnecessários, iremos contribuir com o meio ambiente, evitando a retirada de árvores para produção do dinheiro. Se não gastamos, o dinheiro com certeza vai render.

Assim, ele analisa que um menor consumo gera uma menor produção e, consequentemente, uma menor extração de matérias-primas do meio ambiente. Nesse sentido, entendemos que a ação não se refere a uma prática sustentável - com a qual nunca haviam feito a ligação - mas intenta unicamente controlar seus gastos, o que condiz com as respostas da maioria dos entrevistados; assim como é possível discernir que a visão da ajuda ao meio-ambiente é limitada quanto ao que pode ser praticado com esse fim.

Em relação a favorecer sua própria economia e, como consequência, ajudar o meio-ambiente, as respostas abaixo exemplificam a questão:

\#R2-31 -0 controle do dinheiro é importante pois se controlamos o nosso consumo e comprarmos apenas o necessário, a indústria vai começar a produzir também o necessário.

\#R10-153 - Eu nunca pensei nisto. A minha consciência vai depender do tipo de produto. Porque a gente tem o produto bom e o produto ruim. Tem de saber qual destes dois. Comprando menos você vai economizar mais.

Neste ponto, recorre-se ao trabalho de Shingler (2009) e Milyavskaya et al. (2015), ao considerarmos que o desconhecimento dos indivíduos quanto as ações de proteção ao meio ambiente também leva a uma ausência de percepção quanto a visão de prioridade dessa proteção, conduzindo ao entendimento de que a prática da sustentabilidade é um processo involuntário e inconsciente.

Ganhar pouco emergiu vinculado também a função pesquisar melhores preços, levando a ligação dessa prática a uma menor extração de matérias-primas do meio-ambiente. 0 trecho de fala abaixo indica como se deu essa significação. Quando questionada do que faz para controlar seu orçamento, a entrevistada afirma que:

\#R15-219 - Pesquisa de preços; evitar comprar coisas de urgência e se atentar para promoções.

Desse modo, ela julga que essa atitude cuidadosa a faz consumir menos e que, esse tipo de ação, pode gerar uma nação menos predatória, pois deverá reduzir a extração de matérias primas e diminuir o descarte:

\#R15-227 - Acredito que quando se tem uma noção clara dos preços dos produtos que adquirimos conseguimos diminuir o consumo, valorizando o uso da matéria prima e optando por adquirir produtos que sejam mais duráveis. [...] Quanto menos se busca consumir, mais sustentável e menos predatória se torna uma nação. 
Novamente percebemos uma prática relacionada a sustentabilidade como reflexo da consciência de preço, tendo por base a avaliação custo-benefício, assim como se repete na fala as ações benéficas ao meio ambiente como uma consequência do controle monetário.

0 fato de ganhar pouco também teve por função pechinchar para baixar os preços e, comprando menos, da mesma forma, gera um menor descarte no meio-ambiente. Em sua maioria, quando os entrevistados fazem comparação de preços ou praticam alguma negociação, buscam, da mesma forma, seu bem-estar econômico (Shin \& Ji, 2021). 0 respondente de número 11 afirma ser disciplinado com seu orçamento, pois ganha pouco. Costuma fazer pesquisas de preço e barganhar nas negociações. A relação que estabelece a partir de sua ação é que essa gera menos consumo, portanto, menos descarte:

\#R11- 161 - Eu pechincho, isso é uma forma de poupar meu dinheiro. [...] Diminuir o consumismo gera-se um impacto, quanto mais você comprar irá gerar lixos, gera poluição.

Conforme com a narrativa, os respondentes demonstraram que o autocontrole e a consciência de preço são dois elementos presentes na organização financeira. Entretanto, diferente do vínculo apresentado por Locke e Lathan (2002), o controle não está diretamente relacionado à autodisciplina econômica, mas sim pelo fato de ganharem pouco, pela responsabilidade com o orçamento doméstico e pela dificuldade em ganhar o recurso, fatores motivadores descritos nas categorias de avaliação. Esses achados remetem ao que Hemais et al. (2014) abordam sobre os consumidores de baixa renda, de que os indivíduos dessa amostra apresentam limitado planejamento financeiro mensal, mas entendem a necessidade de fazê-lo.

Ao mesmo tempo, também podemos perceber que os respondentes entendem que produtos de qualidade, apesar de serem mais caros, diminuem a necessidade da efetivação de uma nova compra em curto de espaço de tempo. Essa perspectiva demonstra que a análise custo-benefício também se apresenta no processo de decisão dos consumidores de baixa renda, assim como apresentaram Gao, Zhang e Mittal (2017) e Lodi e Hemais (2019). O que nos leva a considerar que para esse perfil de consumidor o esforço financeiro para comprar um produto mais caro, sendo, por exemplo, um produto verde ou ecológico, seria recompensado pela sua durabilidade (Ghali-Zinoubiand \& Toukabri, 2019; Inzlicht et al., 2021).

A pesquisa e a comparação de preço relatada pelos respondentes também expressam uma consciência em relação ao preço dos produtos adquiridos (Shin \& Ji, 2021). A perspectiva de Gan (2015), de consumidores de baixa renda tendem a avaliar preço de produtos, geralmente baseado em informações, em pesquisas e na comparação efetuada entre produtos similares de uma mesma categoria; e de Mortimer e Weeks (2019), de que esses consumidores estão dispostos a gastar parte do tempo em se engajar a procurar por produtos com o custo menor e, comumente, usam as promoções para simplificar mentalmente a consciência de preço, foram identificados nos relatos dos entrevistados. Dessa forma, é possível considerar que mesmo que a ausência de um nível educacional que permita que os indivíduos de baixa renda façam um planejamento financeiro de longo prazo, eles entendem que poupar o dinheiro a partir de uma pesquisa de preços é um meio importante de garantir o pagamento das despesas.

À medida que os respondentes narravam sobre os fatores motivadores do autocontrole e da percepção de preço, foi possível avaliar como essas práticas se relacionam com o consumo ambiental sustentável. Geralmente, essa relação foi identificada a partir de duas significações, a de menor impacto dos resíduos no meio-ambiente (promovido pelo menor descarte e maior controle das ações de consumo) e menos uso de recursos naturais (pela menor extração da matéria-prima para fabricação do produto), algo que vai na linha dos estudos de Bacha, Strehlau \& Schaun (2011), Kraemer, Silveria e Rossi (2012) e Policarpo e Aguiar (2020). Adicionalmente, considerando os relatos dos entrevistados, também é possível identificar que tais significações são resultantes de um comportamento involuntário (Zavestoski, 2002; Lima, Costa e Félix, 2019).

Mesmo analisando a perspectiva de Duckworth \& Gross, (2014) e Baskentli et al. (2019), de que ações involuntárias também se configuram como práticas de comportamento em prol da sustentabilidade, é importante se discutir esses resultados. Essas práticas involuntárias nos levam ao entendimento de que a sustentabilidade ambiental não é o fator motivador principal de suas ações, mas uma consequência percebida como benéfica do controle monetário. No entanto, questionamos, caso os respondentes tivessem recursos em maior abundância, se a perspectiva benéfica ainda seria um fator relevante para o controle do consumo.

Esse pensamento conduz a linha de raciocínio de que não é a classe social que impacta negativamente na sustentabilidade, mas sim o nível de consciência que os indivíduos possuem sobre a importância de se praticar a sustentabilidade, conforme o posicionamento inicial desta investigação 
(Phipps et al., 2013; Milyavskaya et al., 2015; Lodi \& Hemais, 2019; Costa et al., 2021). 0 que pode ser exemplificado pela resposta de um dos respondentes ao ser solicitado para estabelecer a relação entre buscar informações de preço dos produtos e, de algum modo, praticar a sustentabilidade ambiental, relatando que não havia pensado sobre isso ou que não sabiam como fazer essa relação. De fato, o indivíduo, mesmo que de forma limitada, sabia o que se tratava a sustentabilidade, mas não havia relacionado o tema ao melhor planejamento financeiro.

Outro fator que pode auxiliar a exemplificação, é a ausência de uma relação com a sustentabilidade social. Mesmo não sendo o foco do trabalho, por ser conduzida uma investigação exploratória com perguntas abertas, os respondentes poderiam ter levantado informações acerca do aspecto social. 0 que aponta uma visão restrita da sustentabilidade baseado no aspecto ambiental (Pettie \& Collins, 2009).

Ainda assim, é importante destacar que a compra de produtos tendo por base o melhor uso do recurso financeiro também pode ser entendido como benéfico para o meio ambiente a partir da perspectiva do comportamento racional e utilitário. A racionalidade na compra representa uma forma pelos quais os consumidores analisam a necessidade do consumo evitando gastos excessivos ao mesmo que controlam o desperdício, impactando positivamente no meio ambiente onde estão inseridos (Aguiar et al., 2015; Al Mamun et al., 2018; Baskentli et al., 2019; Inzlicht et al., 2021). Ao contrário, a compra por impulso, é entendida como uma ação negativa ao meio ambiente já que estimula o consumo pelo desejo e geram maior descarte no meio ambiente (Dolan, 2002; Figueira \& Pereira, 2014).

\section{Considerações Finais}

As pesquisas em torno da relação entre consumo e sustentabilidade tem recebido crescente atenção no campo do comportamento do consumidor especialmente no sentido de avaliar o que leva os indivíduos ao consumo sustentável. Entretanto, na literatura, comumente, não é destacada a percepção dos consumidores de baixa renda sobre essa relação. Entendendo que esse perfil de consumo tem no fator renda um limitante de seus gastos, buscou-se entender como esses consumidores estabelecem a relação entre o autocontrole das despesas, a consciência de preço e o consumo sustentável. Ressalta-se a importância da realização desta pesquisa no intuito de trazer luz para comunidade científica e sociedade geral da importância das práticas socioambientais dos consumidores de baixa renda e, ao mesmo, despertar nos respondentes a necessidade de se pensar sobre a sustentabilidade nos momentos de consumo.

Dessa forma, entendemos como a principal contribuição do estudo que a relação que os consumidores de baixa renda estabelecem com o consumo sustentável é derivada de uma percepção limitada da sustentabilidade, voltadas na sua maioria para as práticas ambientais, quer seja por meio da prática de reuso, reciclagem ou pela racionalidade de evitar um consumo que geram desperdícios, e o meio ambiente não é o objetivo principal de suas ações, mas as decisões racionais de consumo, protagonizadas pela consciência de preço e o autocontrole, evitam a compra por impulso e interferem positivamente na proteção ao meio ambiente, resultado esse entendido de forma consciente pelos indivíduos que, ao fazê-lo, acreditam despertar o desejo de adoção de novas práticas ambientais.

Esse estudo mostrou, que os consumidores de baixa renda, têm conhecimento sobre o preço dos insumos que vão consumir, assim como, tem um autocontrole das despesas (quer seja pela lógica econômica ou pela relação entre custo e benefício). A análise em torno das narrativas dos respondentes mostrou que as ações de autocontrole e consciência levam os indivíduos ao entendimento de que tais ações contribuem com o comportamento em prol da sustentabilidade pelo menor descarte do lixo no meio ambiente, pelo controle do consumo influenciando as causas ambientais e pela menor extração da matéria-prima do meio ambiente

Quando os consumidores têm práticas condizentes com uma racionalidade de seus gastos por meio do controle com compras em excesso e pela compra de produtos com maior durabilidade, estes entendem que gera um impacto positivo no meio ambiente que estão inseridos. Consequentemente, estão desenvolvendo práticas de consumo sustentável, embora essa percepção não tenha sido evidenciada como prioritária pelos respondentes desta investigação. 0 que nos leva a pensar que, ainda que não tenham plena ciência dos efeitos de suas ações, os indivíduos, em seus hábitos rotineiros, acabam por desenvolverem práticas que comumente só são percebidas ou averiguadas em consumo de bens sustentáveis em larga escala. O conhecimento limitado da sustentabilidade também enaltece a necessidade de uma melhor educação sobre o tema, assim como as formas que suas práticas podem ocorrer. Conforme indica Prahalad (2006), geralmente as pessoas de baixa renda desconhecem os benefícios que determinados produtos e serviços podem trazer, resultando, inclusive, na melhora de sua saúde e bem-estar. Por possuírem restrito acesso a informações, sabem pouco sobre novos e mais avançados produtos, deixando de comprá-los. Gestores, 
privados ou públicos, podem contribuir com esse processo, trabalhando em suas ações comunicativas informações apropriadas para elevar o nível de conhecimento sobre a sustentabilidade, assim como fornecer insumos necessários para que a mesma possa ser conduzida.

Adicionalmente, esse estudo também buscou redirecionar o olhar dos estudos do marketing para esse público-alvo e apontar que a sustentabilidade não deve ser entendida apenas do ponto de vista de compra de produtos específicos que tenham rótulos sustentáveis, mas sim das atitudes que os indivíduos possuem no seu cotidiano sobre o tema e sobre a capacidade e o desejo de mudar o comportamento para um mais sustentável.

Com essa visão, sugere-se aqui que novas pesquisas sejam conduzidas com pessoas de baixa renda utilizando outros elementos que influenciam seu comportamento em torno da sustentabilidade, como a normas sociais, crenças e a cultura. Como limitações dessa pesquisa, entendemos que o fato de nos restringirmos a um município foi um ponto potencialmente capaz de restringir os achados, apesar de termos tido o cuidado de buscar variações nos respondentes em termos de profissão, idade e gênero. Indicamos que essa proposta seja explorada por estudos em outros Estados do país e que sejam coletados dados tanto em municípios do interior como nas suas capitais, para observar se acontecem diferenças de comportamento e como elas se relacionam ao que encontramos nessa pesquisa. Contudo, acreditamos que nossa contribuição teórica esteja no fato de relacionar a temática às práticas do consumidor de baixa renda; e, como antecipamos, em termos de implicações práticas, esperamos que ao fazermos as pessoas de baixa renda relacionarem suas práticas de consumo às questões de sustentabilidade, possamos despertá-las para importância da temática, sendo essa urgente, relevante e dependente do exercício de todos para que, mesmo que minimamente, se efetivem e promovam a diferença para a sobrevivência do planeta.

\section{Referências}

Aguiar, E. C., Farias, S. A, Gomes, V. M., \& Santos, J. G. (2015). Percepção de crowding e comportamento do consumidor: uma abordagem não linear no varejo supermercadista de baixa renda. Revista de Administração da UNIMEP - RAU, 13 (3), 207 - 229.

Al Mamun, A., Mohamad, M. R., Yaacob, M. R. B., \& Mohíuddin, M. (2018). Intention and behavior towards green consumption among low-income households. Journal of Environmental Management, 227, 73-86.

Anderson, J., \& Markides, C. (2007). Strategic innovation at the base of the pyramid. MIT Sloan Management Review, 49 (1), 83.

Antonetti, P., \& Maklan, S. (2014). Feelings that make a difference: How guilt and pride convince consumers of the effectiveness of sustainable consumption choices. Journal of Business Ethics, 124 (1), 117-134.

Bacha, M. L., Strehlau, V. I., \& Schaun, A. (2011). Consumidor Consciente da Renda Baixa: Uma Proposta de Segmentação. Revista Brasileira de Marketing - ReMark, 10 (3), 67-83.

Baskentli, S., Sen, S., Du, S., \& Bhattacharya, C. B. (2019). Consumer reactions to corporate social responsibility: The role of CSR domains. Journal of Business Research, 95, 502-513.

Bauer, M. W., \& Aarts, B. (2002). A construção do corpus: um princípio para a coleta de dados qualitativos. In: M. W. Bauer \& E G. Gaskell (Eds.). Pesquisa qualitativa com texto, imagem e som: um manual prático. Petrópolis: Vozes.

Beck, C. G., \& Pereira, R. C. F. (2012). Preocupação Ambiental e Consumo Consciente: Os Meus, os Seus e os Nossos Interesses. Revista de Gestão Ambiental e Sustentabilidade, 1(2), p. 51-78.

Binkley, J. K., \& Bejnarowicz, J. (2003). Consumer price awareness in food shopping: the case of quantity surcharges. Journal of Retailing, 79 (1), 27-35.

Chauvel, M. A. \& Mattos, M. P. A. Z. (2008). Consumidores de baixa renda: Uma revisão dos achados de estudos feitos no Brasil. CADERNOS EBAPE.BR, 6(2),1-17.

Costa, M. F. da, Silva, D. W. O. da, \& Campos, P. de O. (2020). Percepção de Preço, Autocontrole e Arrependimento Pós-Compra: Um Estudo Com Consumidores de Compra Coletiva. Revista Interdisciplinar De Marketing, 10(2), 121-137.

Costa, C. S., Costa, M. F da, Maciel, R. F., Aguiar, E. C, \& Wanderley, L. O. (2021). Consumer antecedents towards green product purchase intentions. Journal of Cleaner Production, 313 (1), september, 127964.

Creswell, J. W. (2007). Projeto de pesquisa: métodos qualitativo, quantitativo e misto. 2. ed. Porto Alegre: Artmed.

Damázio, L. F., Coutinho, L. A. N. \& Shigaki H. B. (2020). Comportamento do consumidor em relação a produtos sustentáveis: uma revisão sistemática de literatura. Revista Eletrônica de Ciência Administrativa, 19(3), 374-392 
Denzin, N. K., \& Lincoln, Y.S. (1994). Handbook of qualitative research. Thousand Oaks: Sage Publications.

Dolan, P. (2002). The sustainability of sustainable consumption. Journal of Macromarketing, 22 (2), 180-181.

Duckworth, A.; \& Gross, J. J. (2014). Self-control and grit: Related but separable determinants of success. Current Directions in Psychological Science, 23, 319-325.

Figueira, R. F., \& Pereira, R. C. (2014). Devo, Não Nego, Pago Quando Puder: Uma Análise Dos Antecedentes Do Endividamento Do Consumidor. Revista Brasileira de Marketing - ReMark, 3 (5), 124- 138.

Gerhard, F., Sousa, T. M. P., Souza, L. F. \& Peñaloza, V. (2016). Análise das influências sociodemográficas na atitude de compra dos consumidores de baixa renda. Organizações em Contexto, 12(23), 243-279.

Ghali-Zinoubiand, Z., \& Toukabri, M. (2019). The antecedents of the consumer purchase intention: Sensitivity to price and involvement in organic product: Moderating role of product regional identity. Trends in Food Science \& Technology, 90, 175-179.

Gathergood, J. (2012). Self-control, financial literacy and consumer over-indebtedness. Journal of Economic Psychology, 33 (3), 590-602.

Gao, H., Zhang, Y., \& Mittal, V. (2017). How Does Local-Global Identity Affect Price Sensitivity? Journal of Marketing, 81 (3), 62-79.

Gan, S. S., Pujawan, I. N., \& Suparno, W. B. (2015). Pricing decision model for new and remanufactured short-life cycle products with time-dependent demand. Operations Research Perspectives, 2, 1-12.

Gil, A. C. (2008). Métodos e técnicas de pesquisa social. São Paulo: Ed. Atlas S.A.

Gill, R. (2002). Análise de discurso. In: M. W. Bauer E G. \& Gaskell (Eds.). Pesquisa qualitativa com texto, imagem e som: um manual prático. Petrópolis: Vozes.

Hemais, M. W., Borelli, F. C., Casotti, L. M., \& Dias, P. I. (2014). Economia, Marketing e Indivíduos de Baixa Renda: o interesse após uma história de indiferença. Revista de Ciências da Administração, 16 (39), 49-64.

Inzlicht, M., Werner, K., Briskin, J. L., \& Roberts, B. (2021). Integrating models of self- regulation. Annual Review of Psychology, 72, 1-27.

Kraemer, F., Silveira, T., \& Rossi, C. (2012). Evidências cotidianas de resistência ao consumo como práticas individuais na busca pelo desenvolvimento sustentável. Cadernos EBAPE.BR, 10 (3), 677-700.

Lima, E. B., Costa, C. S., \& Félix, G. R. (2019). Guilt and pride emotions and their influence on the intention of purchasing green products. Consumer Behavior Review, 3 (2), 70-84.

Lim, W. M., Ting, D. H., Ng, W. K., Chin, J. H., \& Boo, W. A. (2013). Why green products remain unfavorable despite being labelled environmentally-friendly? Contemporary Management Research, 9, 35-46.

Lim, W. M. (2017). Online group buying: Some insights from the business-to-business perspective. Industrial Marketing Management, 65, 182-193.

Lens, W., Simons, J., \& Dewitte, S. (2001). Student motivation and self-regulation as a function of future time perspective and perceived instrumentality. In S. Volet \& S. Järvelä (Eds.), Motivation in learning contexts: Theoretical advances and methodological implications. Pergamon Press, 233-248.

Locke, E. A., \& Latham, G. P. (2002). Building a practically useful theory of goal setting and task motivation: A 35-year odyssey. American Psychologist, 57, 705-717.

Lodi, R. J., \& Hemais, M. W. (2019). Consumidores de baixa renda e o seu eu estendido em carros: Uma pesquisa interpretativista. Revista de Administração Unimep - RAU, 17 (2) Ed. Especial, maio-agosto.

Milan, G. S., Toni, D. D., Lima, V. Z., \& Eberle, L. (2017). Papel Moderador da Marca e Mediação do Valor Percebido na Intenção de Recompra. RAC - Revista de Administração Contemporânea, 21 (3), 347-372.

Milyavskaya, M., Inzlicht, M., Hope, N., \& Koestner, R. (2015). Saying "no" to temptation: Want-to motivation improves self-regulation by reducing temptation rather than by increasing self-control. Journal of Personality and Social Psychology, 109, 677-693.

Mortimer, G., \& Weeks, C. S. (2019). How unit price awareness and usage encourages grocery brand switching and expenditure. Journal of Retailing and Consumer Services, 49, 346-356.

Nielsen, K. S., \& Hofmann, W. (2021). Motivating sustainability through morality: A daily diary study on the link between moral self-control and clothing consumption. Journal of Environmental Psychology, 73, 101551.

O’Donoghue, T. D., \& Rabin, M. (2001). Choice and procrastination. Q. J. Econ. CXVI, 121-160.

Pacheco, P. H. B. (org.). (2019). As vertentes do consumo sustentável: Um estudo comparativo entre consumidores com formação ambiental e consumidores em geral. Gestão e Desenvolvimento, 16(1).

Paiva, F. G. Leão, A. L. M. S., \& Mello, S. C. B. (2011). Validade e confiabilidade na pesquisa qualitativa em Administração. Revista de Ciências da Administração, 13 (31), 190-209. 
Phipps, M. Ozanne, L. K., Luchs, M., Subrahmanyan, S., Kapitan, S., Catlin, J., Gau, R., Naylor, R. W., Rose, R., Simpson, B. Weaver, S. T. (2013). Understanding the inherent complexity of sustainable consumption: a social cognitive framework. Journal of Business Research, 66 (8), 1227-1234.

Policarpo, M. C, \& Aguiar, E. C (2020). How self-expressive benefits relate to buying a hybrid car as a green product. Journal of Cleaner Production, 252, 119859.

Prahalad, C. K. (2006). The fortune at the bottom of the pyramid: eradicating poverty through profits. New Jersey, USA: Pearson Education.

Peattie, K., \& Collins, A. (2009). Guest editorial: Perspectives on sustainable consumption. International Journal of Consumer Studies, 33 (2), 107-112.

Romani, S., Grappi, S., \& Bagozzi, R. P. (2013). Explaining consumer reactions to corporate social responsibility: The role of gratitude and altruistic values. Journal of Business Ethics, 114 (2), 193-206.

Sachs, J. (2005). The end of poverty: economic possibilities for our time. New York: Penguin.

Shin S., \& Ji, S. (2021). Consumers' Willingness to Purchase Imported Cherries towards Sustainable Market: Evidence from the Republic of Korea. Sustainability, 13 (10), 5420.

Shingler, J. (2009). Long term study of pennsylvania's low-income usage reduction program: Results of analyses and discussion. Consumer Services Information System: Penn State University: College State, PA.

Silva, J. C. P. \& Neto, A. R. (2018). Determinantes da decisão de compra da baixa renda. Revista Pensamento Contemporâneo em Administração- RPCA, 12(1), 89-104

Tamer, A. (2011). Environmental segmentation alternatives: buyers' profiles and implications. Journal of Islamic Marketing, 2 (1), 55-73.

Vohs, K. D., \& Baumeister, R. F. (2004). Understanding self-regulation: An introduction. Handbook of self-regulation. Research, theory and applications, 1-9.

Vosgerau, J., Scopelliti, I., \& Huh, Y. E. (2020). Exerting self-control $\neq$ sacrificing pleasure. Journal of Consumer Psychology, v. 30 (1), 181-200.

Yang, Z. (2019). How does consumers' local or global identity influence price-perceived quality associations? The role of perceived quality variance. Journal of Marketing, 83 (3), 145-162.

Zavestoski, S. (2002). Guest editorial: anticonsumption attitudes. Psychology \& Marketing, 19 (2), 121-126. 